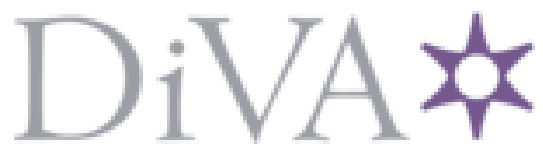

http://www.diva-portal.org

This is the published version of a paper published in Behavior and Information Technology.

Citation for the original published paper (version of record):

Zhang, X., Chen, Q. (2021)

Towards an understanding of the decision process of solvers' participation in crowdsourcing contests for problem solving

Behavior and Information Technology, : 1-19

https://doi.org/10.1080/0144929x.2021.1941258

Access to the published version may require subscription.

N.B. When citing this work, cite the original published paper.

Permanent link to this version:

http://urn.kb.se/resolve?urn=urn:nbn:se:kth:diva-304734 


\section{Towards an understanding of the decision process of solvers' participation in crowdsourcing contests for problem solving}

\section{Xuefeng Zhang \& Qian Chen}

To cite this article: Xuefeng Zhang \& Qian Chen (2021): Towards an understanding of the decision process of solvers' participation in crowdsourcing contests for problem solving, Behaviour \& Information Technology, DOI: 10.1080/0144929X.2021.1941258

To link to this article: https://doi.org/10.1080/0144929X.2021.1941258

曲 Published online: 15 Jun 2021.

Submit your article to this journal $๘$

Џ Article views: 49

Q View related articles ¿

View Crossmark data \lceil 


\title{
Towards an understanding of the decision process of solvers' participation in crowdsourcing contests for problem solving
}

\author{
Xuefeng Zhang ${ }^{\mathrm{a}}$ and Qian Chen ${ }^{\mathrm{b}}$

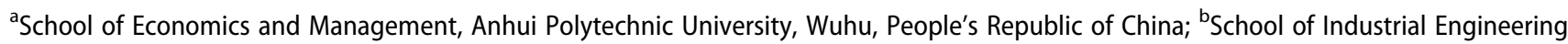 \\ and Management, KTH Royal Institute of Technology, Stockholm, Sweden
}

\begin{abstract}
Solvers' participation is essential for successful implementation of crowdsourcing contests for problem solving (CCPS). Many efforts have been made to investigate solvers' various participation behaviours in CCPS. Whether or not a solver will conduct a behaviour is the result of decision making. However, to our knowledge, few studies concentrated on solvers' participation from a decision process perspective and little is known about the factors that influence the decisions that solvers are likely to make. This study aims to develop a framework for demonstrating solvers' decisions and their relations, thereafter identify the factors that affect each of decision makings. It does so through the qualitative structured interviews conducted with solvers in a crowdsourcing platform. The interviews capture four major interrelated solvers' decisions that are decisions of participation in CCPS, platform selection, contest selection and determination of effort level, respectively. Moreover, the factors including solvers' motives, solvers' individual characteristics and incentives, and their roles in each of solvers' decision makings are presented. The findings improve the understanding of solvers' participation in CCPS from a decision process perspective. With the further comprehending of factors that affect solvers' decision makings, this study provides practical implications for crowdsourcing platforms to improve their services for solvers.
\end{abstract}

\section{ARTICLE HISTORY}

Received 4 May 2020

Accepted 4 June 2021

\section{KEYWORDS}

Crowdsourcing contests; problem solving; solvers participation; decision process framework

\section{Introduction}

Crowdsourcing is a kind of participative online activity in which a large and possibly undefined group of people contribute to the tasks outsourced by requesters through a flexible open call (Estellés-Arolas and González-Ladrón-de-Guevara 2012). Inspired by the financial or non-financial benefits, there is a popular trend that both requesters and solvers are making use of crowdsourcing to handle different possible tasks, especially problem-solving tasks (Bassi et al. 2020; Brabham 2008; Malone, Laubacher, and Dellarocas 2010; Mount, Round, and Pitsis 2020; Schenk and Guittard 2011; Terwiesch and Xu 2008). Regarding the crowdsourcing of problem-solving tasks, contest is an important and widely adopted form (Bockstedt, Druehl, and Mishra 2015; Khasraghi and Aghaie 2014; Terwiesch and $\mathrm{Xu}$ 2008). A large number of online crowdsourcing platforms that support problem-solving contests have been developed and grown rapidly, such as DesignCrowd, 99designs, HYVE Crowd, and ZBJ.

The sustained development of crowdsourcing contests for problem solving (CCPS) and their supporting platforms greatly depend on solvers' active participation (Sun, Fang, and Lim 2012; Wang and Wang 2019; Ye and Kankanhalli 2017). It is, therefore, hardly surprising that academic researchers and practitioners have paid much attention on developing the related theoretical basis and practical implications to understand and stimulate solvers' participation in CCPS. Generally, the solvers' participation can be specialised as several different actions according to their different participation levels. These actions include participating in a crowdsourcing platform (Franke, Keinz, and Klausberger 2013; Heo and Toomey 2015; Mazzola et al. 2020; Zheng, Li, and Hou 2011), engaging in a task (Deodhar 2020; Pee, Koh, and Goh 2018; Schulze, Krug, and Schader 2012), making effort to complete the task (Bockstedt, Druehl, and Mishra 2015; Liang et al. 2018) and developing solutions with good quality (Acar 2019; Garcia Martinez 2017; Liu et al. 2020; Mack and Landau 2020).

To stimulate solvers to conduct these actions, scholars exerted a great deal of effort to identify and examine the factors that influence these actions from internal and

CONTACT Xuefeng Zhang xfzhang1987@ahpu.edu.cn E School of Economics and Management, Anhui Polytechnic University, Beijing Middle Road 8, Wuhu, Anhui, People's Republic of China

(c) 2021 Informa UK Limited, trading as Taylor \& Francis Group 
external perspectives. Specifically, the internal factors mainly include solvers' motivations (Chris Zhao and Zhu 2014; Liang et al. 2018; Wu and Gong 2020), expertise (Mack and Landau 2020; Zhu, Li, and Andrews 2017), participation experience (Bayus 2013; Khasraghi and Aghaie 2014) and cultural background (Bockstedt, Druehl, and Mishra 2015; Chua, Roth, and Lemoine 2015). The external factors such as fairness of requesters and platforms (Franke, Keinz, and Klausberger 2013; Zou, Zhang, and Liu 2015), feedback provided by requesters (Heo and Toomey 2015; Wooten and Ulrich 2017) and task attributes (Mazzola et al. 2018; Steils and Hanine 2019; Vrgović and Jošanov-Vrgović 2017) were identified. Meanwhile, many practical suggestions were developed to attract and encourage solvers to participate and contribute. For example, Kohler (2018) proposed some effective strategies including replicating core interaction, adding new interaction, and extending to new value units. Johnson and Liew Chern (2020) presented four main recommendations of crowdsourcing platform design, which were promoting ease of use, attracting and sustaining solver interest, fostering a community of solvers, and showing solvers' contributions.

Whether or not solvers conduct a participation action is based on their careful decision making. So solvers are likely to make a series of decisions to implement various actions in the whole participation process. In addition, these decisions are not independent of each other but are correlated with each other. For example, Schulze, Krug, and Schader (2012) indicated that individuals generally need to make four decisions, that is, platform selection, task details selection, task choice and work decision while selecting a task to participate. $\mathrm{Li}$ and $\mathrm{Hu}$ (2017) divided solvers' participation in a crowdsourcing contest into two interdependent stages that are decision to register and decision to submit, respectively. Furthermore, some studies classified solver participation process into the decision to participate initially and the decision to participate continuously. Moreover, they argued that the solvers' initial decision results and participation experience potentially affect their later decision outcomes that link to their future participation intention and behaviours (Alam and Campbell 2017; Heo and Toomey 2015; Piezunka and Dahlander 2019; Sun, Fang, and Lim 2012; Wang and Wang 2019). However, the division of solver participation process in the above studies is to some extent too broad to consider some solvers' specific decisions such as task choice and determination of effort level to put into a task. In the meantime, the classification made by Schulze, Krug, and Schader (2012) merely focuses on task selection in the process of solvers' participation. Additionally, to the best of our knowledge, studies which concentrate on solvers' participation in CCPS from a decision process perspective and further investigate major decisions that solvers have to make are so far limited. Moreover, the factors that impact solvers' different decision makings have not yet been gained much attention as well.

In order to fill the above research gap, this study aims to develop a framework for demonstrating the decision process of solvers' participation in CCPS, thereafter identify the factors that affect each decision making in the whole decision process. To achieve the research aims, the model of Motive-Incentive-Activation-Behaviour (MIAB) (Rosestiel Von 2007; Leimeister et al. 2009) is employed as the theoretical ground for constructing the framework. Based on the interviews with solvers in ZBJ, a typical crowdsourcing platform supporting CCPS, this study identifies four major decisions that comprise the decision process of solvers' participation in CCPS. They are: decision to participate in CCPS, platform selection, contest selection, and determination of effort level. Further, in accordance with the MIAB model, three groups of factors, that is, solvers' motives, incentives, and solvers' individual characteristics affecting solvers' decision makings are identified. Our analysis contributes to the understanding of solvers' participation in CCPS from a decision process perspective. In addition, with the comprehending of factors that affect solvers' decision makings, this study provides practical implications for crowdsourcing platforms to serve and manage their solvers.

The rest of this paper is organised as follows. Section 2 presents preliminaries that are related to this study. Section 3 illustrates the research design and method. In Section 4, we present and analyse research results. Discussion of the results, implications for practice, limitations and future research are presented in Section 5. The final section is the conclusion of this paper.

\section{Related work}

\subsection{Crowdsourcing contests for problem solving}

Generally, a crowdsourcing system consists of four major elements. They are: tasks that need to be performed; requesters who publish tasks; solvers who engage in the tasks and platforms where the tasks are published and performed (Bassi et al. 2020 Estellés-Arolas and González-Ladrón-de-Guevara 2012; Malone, Laubacher, and Dellarocas 2010;). Among these elements, tasks play a central role that connects requesters, solvers and platforms together. The problem-solving task as one of the important task types have been 
addressed widely through the way of crowdsourcing (Bassi et al. 2020; Brabham 2008; Terwiesch and Xu 2008). The most common problem-solving tasks include product design, software development, graphic design, ideation and content creation.

In general, problem-solving tasks are complex, not easy to be decomposed apparently, do not have one (or more) correct answer(s), and more importantly their completion relies on skills, knowledge, efforts and creativity of engaged solvers (Mack and Landau 2020; Terwiesch and $\mathrm{Xu} 2008$ ). The major aim of requesters who launch problem-solving tasks in crowdsourcing is to seek solutions that are feasible and can be implemented to handle their problems well. Furthermore, a solver who tries to complete a problem-solving task in crowdsourcing needs to make a certain effort and submit the solutions that satisfy requesters' requirements.

There are two approaches to conduct problem-solving tasks in crowdsourcing, namely integrative approach and selective approach, in terms of the way of obtaining final solutions (Malone et al. 2017; Malone, Laubacher, and Dellarocas 2010; Schenk and Guittard 2011). Specifically, the integrative approach emphasises that the final results are obtained by aggregating all submitted solutions. In contrast, in the selective approach, solvers work independently and then only one or maybe several of them are selected as winners. In practical, the contest is the main representative form of applying selective process to handle problem-solving tasks in crowdsourcing (Segev 2020; Khasraghi and Aghaie 2014).

In this study, we focus on contest-based crowdsourcing for problem solving. Based on descriptions mentioned above, the process of CCPS can be briefly illustrated as following steps: requesters firstly initialise a contest on an online crowdsourcing platform to seek solutions. The contest is launched with its specific requirements including goals, contexts, technical demands, rewards, etc. Then, solvers who are volunteers or are recommended to participate in the contest develop and submit their solutions independently. Finally, those submitted solutions would be evaluated by requesters, and solvers who have provided solutions with superior quality would be selected as winners and awarded.

\subsection{Factors influencing solvers' behaviours in crowdsourcing}

\subsubsection{Solvers' behaviours}

There are two main types of solvers' behaviours in crowdsourcing, which are willingness to participate and actual participation, respectively. To measure the solvers' participation willingness, indicators including registration action (Li and $\mathrm{Hu} 2017)$, task choice (Pee, Koh, and Goh 2018), solution submitting (Chan, Li, and Zhu 2015; Chris Zhao and Zhu 2014) and solvers' self-expressed willingness (Garcia Martinez 2017; Wang, Khasraghi, and Schneider 2020; Zheng, Li, and Hou 2011) were developed. For the solvers' actual participation, it can mainly be specialised as making effort and submitting solutions in a task. More specifically, solvers' effort can be measured by their participation intensity and persistence (Chris Zhao and Zhu 2014) or their physical, cognitive and emotional engagement (Garcia Martinez 2015; Steils and Hanine 2019). Quantity and quality of solutions have been treated as the most important indicators to measure the solvers' behaviour of submitting solutions (Camacho et al. 2019; Huang et al. 2019; Pollok, Lüttgens, and Piller 2019).

\subsubsection{The influential factors}

According to the components of crowdsourcing systems, factors affecting solvers' behaviours can be categorised into four categories. They are solver characteristics, task characteristics, requester characteristics, and platform characteristics, respectively. The detailed information about these four categories of factors is presented in Table 1 .

\section{(1) Solver characteristics}

Motivation has been highlighted as the main aspect of solvers' characteristics that affect their behaviours in crowdsourcing (Mack and Landau 2020; Wu and Gong 2020). It is generally reflected by intrinsic motives including self-efficacy, altruism, a sense of belonging to community, and fun, as well as extrinsic motives including to earn rewards, to develop skills, to improve career prospect, to gain recognition (Acar 2019; Alam and Campbell 2017; Battistella and Nonino 2013; Leimeister et al. 2009). In addition, solvers' characteristics about demographics such as age, gender and employment (Bagheri et al. 2020), participation experience and past success experience (Bayus 2013; Khasraghi and Aghaie 2014), domain knowledge (Frey, Lüthje, and Haag 2011; Mack and Landau 2020; Zhu, Li, and Andrews 2017), and cultural background (Chua, Roth, and Lemoine 2015; Bockstedt, Druehl, and Mishra 2015) have been argued as important factors that affect their behaviours.

\section{(2) Task characteristics}

Task characteristics about task type (Garcia Martinez 2017), complexity and autonomy (Durward, Blohm, and Leimeister 2020; Zheng, Li, and Hou 2011), 
Table 1. The factors influencing solvers' behaviours.

\begin{tabular}{|c|c|}
\hline Categories & Specific factors \\
\hline Solver characteristics & $\begin{array}{l}\text { motives (to earn rewards, to practice skills, to improve career prospect, to gain recognition, to have fun, self-efficacy, altruism, and a } \\
\text { sense of belonging to community); demographics (age, gender, employment); experience (participation experience, past success } \\
\text { experience); domain knowledge; cultural background }\end{array}$ \\
\hline Task characteristics & $\begin{array}{l}\text { type; complexity; autonomy; instruction; prize; payment scheme; in-process status (No. of participated solvers, No. of submitted } \\
\text { submissions and their quality, and feedback and comment) }\end{array}$ \\
\hline $\begin{array}{l}\text { Requester } \\
\text { characteristics }\end{array}$ & $\begin{array}{l}\text { fairness (distribute, procedural, and interactional fairness); identity; feedback (form, content, timing, direction and strength of } \\
\text { feedback) }\end{array}$ \\
\hline $\begin{array}{l}\text { Platform } \\
\text { characteristics }\end{array}$ & system-generated visual feedback; governance mechanisms \\
\hline
\end{tabular}

instruction (Steils and Hanine 2019; Vrgović and Jošanov-Vrgović 2017), prizes and payment scheme (Battistella and Nonino 2012; Jian et al. 2019) have been widely investigated as the factors that affect solvers' behaviours (Jian et al. 2019; Zhu et al. 2019).

\section{(3) Requester characteristics}

Three characteristics of requesters are likely to have influence on solvers' behaviours. The first one is the fairness of requesters which potentially influences solvers' trust in the requesters and further affect solvers' participation willingness and effort (Liu and Liu 2019; Mazzola et al. 2018; Zou, Zhang, and Liu 2015). It is specifically indicated by distribute, procedural and interactional fairness. The second characteristic is requesters' identity which is reflected by their names, financial status, reputation, and experience (Mazzola et al. 2018; Pollok, Lüttgens, and Piller 2019). The last but not the least characteristic is requesters' feedback which would make solvers feel that their contributions are important and do think it as a genuine sign of appreciation (Alam and Campbell 2017; Garcia Martinez 2015). During giving a feedback to solvers, requesters need consider its form (Camacho et al. 2019; Wooten and Ulrich 2017), content (Piezunka and Dahlander 2019), direction and strength (Chan, Li, and Zhu 2015) and timing (Camacho et al. 2019).

\section{(4) Platform characteristics}

The system-generated visual feedback provided by platforms, such as solvers' ranks and reputation scores. It is helpful for increasing solvers' sense of being fairly treated and respected (Boons, Stam, and Barkema 2015; Heo and Toomey 2015). The other characteristic is various governance mechanisms that the platform has for facilitating solvers' to participate and contribute. These mechanisms include offering knowledge integration instructions (Malhotra and Majchrzak 2014), providing recognition from multiple sources (Kohler 2018), providing features for profiling individuals
(Schörpf et al. 2017), setting appropriate service fees (Wen and Lin 2016), and developing effective design toolkits and communication tools (Täuscher 2017).

The solvers' behaviours and detailed factors mentioned above on the one hand provide us a reference to conduct the following interviews and on the other hand help us to explore and categorise the specific factors that influence solvers' decision makings in the whole decision process.

\section{Research design and method}

This section firstly illustrates the MIAB model which is employed as the theoretical basis in this study. Based on this model, interviews with solvers in ZBJ were conducted through a qualitative structured interview method.

\subsection{The MIAB model}

In the field of motivational psychology, individuals who are proactive to achieve a goal could be characterised as motivated person, while individuals who are passive to act can be characterised as unmotivated ones (Ryan and Deci 2000). According the MIAB model (Leimeister et al. 2009; Rosestiel Von 2007), shown in Figure 1, an analogous motive can be activated and subsequently causes a particular behaviour. Activation refers that the individual is responsive to perceived inborn stimuli or external incentives such as monetary rewards and learning.

A set of motives mainly including extrinsic and intrinsic motives are established during an individual's socialisation process. In crowdsourcing, both extrinsic motives (e.g. money, social recognition) and intrinsic motives (e.g. altruism, fun and self-efficacy) play a

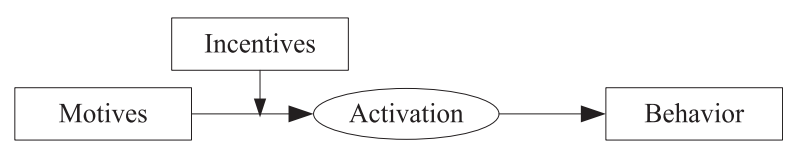

Figure 1. The MIAB model. 
critical role in individuals' decision to participate (Liang et al. 2018; Sun, Fang, and Lim 2012; Zheng, Li, and Hou 2011). In order to match individuals' motives, some incentives should be developed and implemented. Specifically, a particular motive can be matched by one or more incentives. For example, three incentives, that is, access to the knowledge of experts, mentors, and peers are responsive to the motive of learning. The incentive such as appreciation by the organiser and peers could activate individuals' social motives (Leimeister et al. 2009).

\subsection{Research method}

\subsubsection{The research case}

ZBJ (www.zbj.com), founded in 2006, is a typical crowdsourcing platform for problem-solving contests. At present, it has more than 14 million registered solvers. To serve and manage the solvers, ZBJ has implemented the following mechanisms that are related to contest management, solver management and requester management.

(1) Offering various contests. There are three popular categories of problem-solving contests: brand design (logo design, package design and UI design), IT/software development (app and website development), and video production (flash, video and ideation creation).

(2) Having a structured framework for demonstrating a contest. In this framework, context, problem, time scheme, and prize are mandatory parts, while requester's identity and preferences, exemplars, submission evaluation jury and criteria are optional ones.

(3) Managing submissions. The management of submission in a contest covers the journey of submission from its submitting, evaluation, disclosure, to ownership transfer and use. Specifically, at the stage of submitting, a structured format is offered for solvers to develop and demonstrate their submissions clearly. Then, all submitted submissions are evaluated and winners are selected by requesters. Thereafter, the winning submissions are disclosed by the platform and transferred to the requesters. However, solvers who are not winners decide whether or not to disclose their submissions.

(4) Giving feedback. Requesters give feedback to solvers by rating their submissions, declining unsuitable submissions, publishing news and supplementary materials, and communicating with engaged solvers. Unfortunately, solvers especially who are not winners always do not get any feedback from requesters. In addition, it is rare for a solver to get feedback from other solvers.

(5) Providing multiple ways to participate. Three approaches are provided for solvers to participate in ZBJ. The first one is bid-based approach in which requesters can select only one solver as the winner in their launched contests. The second approach is similar to the first, but requesters can select multiple winners. The last one is called tournaments that are launched by big firms or government agencies and generally with a large amount of prize. Requesters can select one or more winners in a tournament.

(6) Offering financial benefits and charging fees. Solvers can earn a prize if they win a contest. Meanwhile, some fees may be charged from solvers, including member fees ( 0 for entry-level solvers, CNY 888 or CNY 666/month for mid and toplevel solvers), service fees (solvers who won a contest have to pay $20 \%$ rewards), taxes and possible cost during payment, and the deposit suggested by ZBJ.

(7) Developing a solver showcase system. It contains solvers' personal information system and star solvers' showcase system. The former presents solvers' basic information, interests, skills, and participation history and performance. The later publishes a list of TOP 100 solvers who have good performance in each category of contests.

(8) Grading solvers and serving them differently. ZBJ grades solvers based on their membership levels and performance records, respectively. A membership fee is required if solvers want to raise their membership levels. The performance records include the number of submitted submissions, the number of won contests, and requesters' reviews. Solvers with different grades enjoy different rights like prioritised support, less service fees and increased client visibility across the platform.

(9) Having a solver support system. Technique support and participation support act as the main components of this system. The technique support in ZBJ introduces tips, tricks, exemplars or successful submissions to solvers in order to assist them to develop submissions as well as train and improve their skills. Additionally, the participation support aims to facilitate and support solvers to conduct activities. It mainly contains FAQ-knowledge base, illustrations of how to participate, contest integrity policy and code of conduct.

(10) Disclosing requesters' identity. Disclosure of requesters' identity in a contest actually depends 
Table 2. The profiles of respondents.

\begin{tabular}{|c|c|c|c|c|c|c|c|c|}
\hline ID & Gender & Age & Education & Major/Skill & Participated tasks & $\begin{array}{l}\text { No. of participated } \\
\text { tasks }\end{array}$ & $\begin{array}{l}\text { No. of accepted } \\
\text { solutions }\end{array}$ & Employed \\
\hline 1 & Male & 28 & 2 & Handwork and design & Logo and graphic design & 239 & 46 & No \\
\hline 2 & Female & 23 & 3 & Visual communication & Food packaging design & 1 & 0 & No \\
\hline 3 & Male & 36 & 3 & Industrial design & Product design & 255 & 24 & Yes \\
\hline 4 & Female & 28 & 1 & Video production & $\begin{array}{l}\text { Logo design and video } \\
\text { production }\end{array}$ & 5 & 0 & Yes \\
\hline 5 & Male & 30 & 2 & Graphic design & Logo and VI design & 3 & 0 & Yes \\
\hline 6 & Female & 28 & 4 & $\begin{array}{l}\text { Cultural industry } \\
\text { management }\end{array}$ & Logo and slogan design & 30 & 2 & Yes \\
\hline 7 & Female & 24 & 2 & Interior design & Logo and poster design & 3 & 0 & Yes \\
\hline 8 & Male & 26 & 2 & Fashion design & Logo and slogan design & 2826 & 350 & No \\
\hline 9 & Male & 37 & 2 & Graphic design & Logo design & 993 & 2 & Yes \\
\hline 10 & Female & 26 & 3 & Visual communication & Logo design & 1 & 0 & No \\
\hline 11 & Female & 33 & 3 & $\begin{array}{l}\text { Administrative } \\
\text { management }\end{array}$ & $\begin{array}{l}\text { Brand stories writing and slogan } \\
\text { design }\end{array}$ & 654 & 108 & Yes \\
\hline 12 & Male & 32 & 3 & Ceramic design & Postcard and logo design & 8 & 3 & Yes \\
\hline 13 & Female & 25 & 1 & Graphic design & Logo design & 1 & 0 & Yes \\
\hline 14 & Male & 35 & 2 & Graphic design & Logo design & 10,042 & 152 & No \\
\hline 15 & Male & 29 & 2 & Graphic design & Logo and package design & 6 & 0 & Yes \\
\hline 16 & Male & 23 & 2 & Graphic design & Poster and business card design & 20 & 11 & Yes \\
\hline 17 & Female & 24 & 1 & Arts and crafts & Logo design & 2 & 0 & Yes \\
\hline
\end{tabular}

Note: education: 1: secondary vocational school; 2: 2-3 years of college; 3 : undergraduate; 4: graduate.

on contest types and requesters themselves. Generally, requesters who are big brands and government agencies may disclose their identity and what they have done on their tournament pages. However, for the general contests launched by smalland medium-size enterprises and individuals, only their nicknames are always displayed.

(11) Requiring prize guaranteed. It intends to ask requesters who are willing to launch a contest to pay contest prizes before it opens to solvers. The pre-paid prizes are kept by the platform. Solvers receive prizes from the platform if they are selected as winners in a contest. It is helpful for avoiding a cheating situation that requesters delaying or even not paying. A label of 'guaranteed' is marked on the contests that have been paid in advance.

In a word, the above-mentioned mechanisms developed by ZBJ for solvers help us to understand solvers' replies in their interviews. In addition, some of mechanisms are similar to the mechanisms in other wellknown crowdsourcing platforms such as 99designs, Designcrowd, Freelancer, Logomyway and Crowdspring. Thus, to some extent, the findings of this study have a valuable reference for these similar platforms.

\subsubsection{Data collection}

The interviewees were mainly selected from an online community consisting of solvers in ZBJ. They are ones who have signed up and participated in at least one contest. In the middle and final of an interview, each respondent received CNY 100 (about 15 dollars) in total. We finally got responses from 17 solvers. Specifically, six respondents were from the community and the rest was recommended by them. Table 2 shows the respondents' profiles.

The interview with a solver was designed to contain three parts: (1) collecting the respondent's basic information; (2) drawing the decision process of the respondent's participation and the factors that influence his/ her decision making and (3) investigating the respondent's intention to participate continuously and the difference of influential factors between his/her initial and afterward participation.

There are 12 major questions in the latter 2 parts. They are: (1) How did you know crowdsourcing? (2) What (motives/reasons) drove your participation? (3) Why did you select ZBJ, did you compare it with other platforms, which ZBJ's features influence your choice? (4) Could you briefly describe the process of your participation in ZBJ? (5) What kinds of contests have you participated? (6) Why did you select these contests? In other words, what factors did you consider when selecting these contests? (7) Did you do your best to complete all of your selected contests or just some of them? and Why? (8) During participating in a contest, did you look into or comment other submitted solutions? (9) Will you participate in ZBJ continuously? (10) If no, why? If yes, are there changes of your motives? (11) Will you participate in contests that are similar to the previous contests? Are there changes of criteria when you select a contest? (12) Is there an impressive thing or moment happened during your participation, and what is it?

All interviews were held through Wechat or Tecent QQ. 13 respondents were interviewed through voice 
calling, while the rest was done through text chat. Each interview took at least $35 \mathrm{~min}$. Data about the respondents' background information was also collected from the platform's webpages and their personal information systems. It can aid to analyse respondents' answers and further connect those answers with ZBJ's components and features.

\subsubsection{Data extraction}

This study employed a data-extraction form to collect and sort the original data, that is, respondents' answers. It contains three parts of information: respondents' personal information (e.g. educational background, skills, the number of participated contests and the number of won contests); respondents' decisions to initially participate (e.g. the way of knowing crowdsourcing; motives to participate; the incentives that influence respondents' platform selection, contest selection and determination of effort level in the selected contests) and respondents' decisions to continuously participate (the extracted information in this part is similar to the information in the second part).

For the respondents' answers in the form of voice calling, we listened to them carefully and further translated them into texts. Thereafter, the texts were filled into a data-extraction form. With respect to textual answers, we comprehended and filled them into a data-extraction form as well. Transforming a respondent's answers into data-extraction form was conducted immediately after an interview in order to reflect his/her actual meaning effectively. For the translated texts, we sent them back to the interviewees for reviewing. The interviewees often concurred with our transcriptions with only minor adjustments required. In addition, we would interview a respondent again and update his/ her data-extraction form if we find some important information that needs to be supplemented after interviewing a new respondent. To summarise, the interview process is an iterative process in order to acquire comprehensive and accurate information.

All the interviews were conducted and recorded in Chinese. When we summarised and presented our research findings in this paper, we translated them into English seriously on the basis of our expertise in the crowdsourcing field and our understanding of respondents' answers. Further, we transferred respondents' answers into texts manually. It is a feasible way when the number of respondents is not large and some of respondents' answers have special meanings under particular contexts. For instance, 'weike' represents solvers. 'zhu seven jie' demonstrates that a respondent's level is seven according to his/her performance. As another example of jargon responses, a few respondents said that some requesters are 'kaopu' which means that they are reliable and trustworthy.

\section{Results analysis}

\subsection{A description of the decision process framework}

This study introduces decision nodes to represent solvers' decisions. Figure 2 presents a general decision node, which includes alternatives, adopted actions, solvers' motives, incentives, and solvers' individual characteristics.

Alternatives refer to the options that solvers can choose when addressing a decision problem. The adopted actions act as decision results that are influenced by three groups of factors, that is, solvers' motives, incentives and solvers' individual characteristics. Specifically, motives activate solvers to have a desire to implement an action (Leimeister et al. 2009). Incentives are those that appeal to solvers' motives for acting (Leimeister et al. 2009; Zhang 2008). Individual characteristics affect solvers' decision makings by determining their motives, influencing their perception of incentives, and affecting their understanding of decision problems.

Based on the decision node introduced above, we develop the decision process framework of solvers' participation in CCPS as shown in Figure 3.

Four decisions involve in the developed decision process framework. The first is 'decision to participate in CCPS', which indicates that a solver has an intention to participate in CCPS. The followed decision, that is, 'platform selection', means that solvers choose a crowdsourcing platform focusing on problem-solving contests from a pool of similar platforms. Thereafter, solvers may select a contest launched on the selected platform to participate and contribute. This decision is referred to as 'contest selection'. At the decision of 'determination of effort level', solvers will determine effort level that they will invest on the selected contest.

It can be seen that these four decisions link together sequentially. The latter decision can only be made after its former decisions have been handled. The result of a former decision has influence on its latter decision

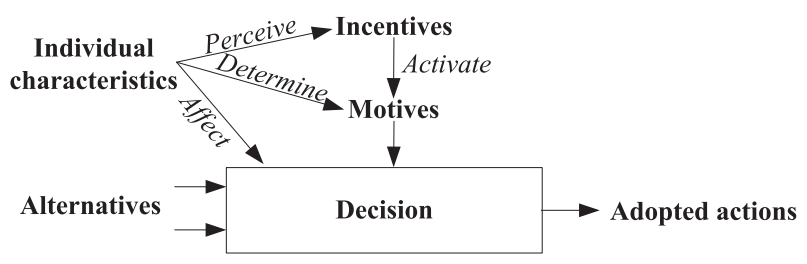

Figure 2. A general decision node. 


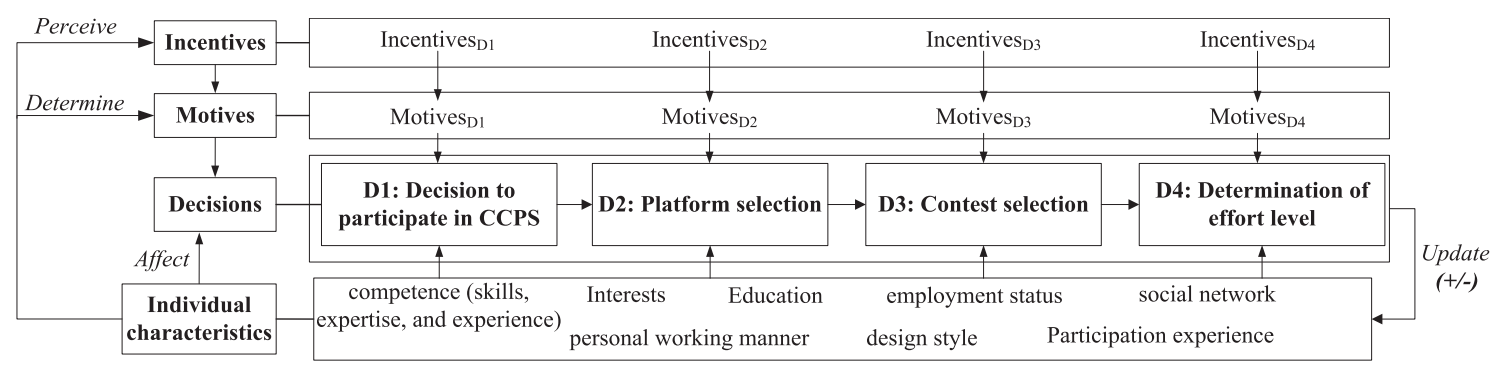

Figure 3. The decision process framework.

makings. However, a solver does not have to go through all these four decisions. Practically, many solvers just register on a crowdsourcing platform but do not undertake any further actions such as participating in a contest or submitting a solution. In contrast, some solvers contribute a lot and become the efficient contributors.

Under each decision, different motives, incentives and individual characteristics work together to determine decision results. However, it is difficult to identify all the specific influential factors and to distinguish a certain influential factor to be pertinent to only one decision, as they could be overlapped in multiple decisions. Thus, this study presents the major influential factors and places them to the closely related decisions.

Additionally, there is a loop existed among the four decisions. Solvers who have gone through the whole process need to start a new loop to make these four decisions again if they intend to participate continuously. Apparently, for a solver, his/her motives, concerned incentives and individual characteristics may be different in his/her initial participation and continuous participation. More specifically, a solver's individual characteristics including skills, interests and participation experience would be updated along with the accumulated participation times. It thus potentially change the solver's motives and perception of various incentives, which might positively or negatively influence his/her each decision making in the next loop.

\subsection{Decision to participate in CCPS}

The factors that affect solvers' decision to participate in CCPS are illustrated below.

\section{(1) Motives}

Table 3 presents the motives of respondents to participate in CCPS initially and continuously.

In the initial participation, 'to earn rewards' is the most highlighted motive (16 respondents). The one who did not have this motive was a student (ID2) aiming to develop skills through solving real problems. The following motives are 'to develop skills' (8 respondents), 'to improve career prospects' (7 respondents), and 'to have fun' (4 respondents). Only one respondent (ID6), a graduate student who thought that she was brilliant enough to develop creative ideas had the motive of 'self-efficacy'. In addition, the number of respondents (11 respondents) who had multiple motives is larger than those (6 respondents) who had a single motive. For the respondents having multiple motives, the order of motives is different. For example, a respondent (ID10) ranked her motives in order of importance: 'to earn rewards', 'to develop skills' and 'to improve career prospects'. Nevertheless, 'to develop skills' has a higher priority than 'to earn rewards' for the respondent ID15.

Furthermore, 2 out of 17 respondents definitely said that they would not participate in CCPS further. While the rest of 15 respondents showed their intention to continuously participate in CCPS. However, one thing needs to be highlighted here is that the motives of those 15 respondents had some changes comparing to their initial participation. Specifically, improving career prospects was one of 4 respondents' motives in the initial participation, but was not one of their motives any more in the continuous participation. The major reason is that they had an established career direction and a formal job. In contrast, 2 respondents added new motives. For example, a respondent (ID2) added

Table 3. Respondents' motives to participate in CCPS initially and continuously.

\begin{tabular}{lcc}
\hline & \multicolumn{2}{c}{ No. of respondents } \\
\cline { 2 - 3 } Motives & $\begin{array}{c}\text { Initial } \\
\text { participation }\end{array}$ & $\begin{array}{c}\text { Continuous } \\
\text { participation }\end{array}$ \\
\hline To earn rewards & 6 & 6 \\
$\begin{array}{l}\text { To earn rewards, to develop skills, } \\
\text { to improve career prospects }\end{array}$ & 5 & 0 \\
To earn rewards, to develop skills & 2 & 5 \\
To earn rewards, to have fun & 1 & 0 \\
To earn rewards, to have fun, self- & 1 & 2 \\
$\quad$ efficacy & & 0 \\
To earn rewards, to have fun, to & 1 & 0 \\
$\quad$ improve career prospects & & 2 \\
To have fun, to develop skills & 1 & \\
To earn rewards, to develop skills, & 0 & \\
to have fun & & \\
\hline
\end{tabular}


'to earn rewards' as one of her motives because she has graduated and wanted to live better. The other respondent (ID8) added the motive of 'self-efficacy' because of the positive influence from a few successful participations.

As a consequence, a solver's motives have evolved from initial participation to continuous participation. In addition, it can be seen that a few motives introduced in Table 2 were not mentioned by the respondents, such as 'to gain recognition', 'altruism' and 'a sense of belonging to community' One possible reason for this absence is that these respondents were at beginning of involving in CCPS and they thought that it can only aid them to learn and earn money. This understanding would make them rarely explore other potential benefits from participating in CCPS. Another possible reason is that ZBJ did not build a good social community that results in limited interactions happened among solvers and requesters.

\section{(2) Incentives}

According to our interview results, 9 respondents knew CCPS through their friends and mentors, while the rest 8 respondents got to know it through advertisement promotions on websites or TV recruitment programmes. Four types of information were generally contained in the above recommendations and promotions. They are: what is CCPS; what recommenders have experienced in a specific CCPS platform; what solvers can do and get in the specific crowdsourcing platform; how to participate and contribute in the platform.

For the solvers who accepted their friends'/mentors' suggestions or recommendations, their intimate relation with and trust in these recommenders play a critical role in making a decision to participate, as the respondents (ID1, ID2, ID4, ID5 and ID9) explained:

I trust my friend. He is very reliable and would not entrap me. Further, his experience in $\mathrm{ZBJ}$ verified that this platform can be trusted.... My teacher has a ground expertise in visual communication. We thought that his suggestion of earning and practicing on crowdsourcing platforms deserve to try.

Another important incentive is the fitness between the benefits that solvers may be gained by participating in CCPS and solvers' properties and expectations. Generally, five kinds of fitness were judged by solvers when making a participation decision. They are payment fitness, enjoyment fitness, learning fitness, interest and ability fitness, and flexibility fitness. The former three fitness refer to whether or not the CCPS model can provide solvers opportunities to satisfy their expectations such as 'to earn rewards', 'to have fun' and 'to develop skills'. Regarding the fourth fitness, solvers match their interests and capabilities with published problem-solving contests on a crowdsourcing platform. The last fitness indicates the flexibility of time and ways that the CCPS model provides for solvers to participate. It is concerned by solvers especially those who have a formal job when making a decision to participate in CCPS.

Crowdsourcing models offer us opportunities to utilize our pastime to earn money and practice our design ability. We don't have to go to the office or stay at a specific workplace. We can work at any time and any place ... It is nice to solve real design problems, which not only can practice what we have learned but also recognize design trends. It would be much better if the platform can develop an APP for us to check contest status rather than having to login into the website.

To sum up, the incentives activating solvers' decision to participate in CCPS are opportunities of getting some benefits such as earning money and learning, and the flexibility of obtaining access to these opportunities, respectively. As for the ways that solvers know the CCPS model, they just act as a trigger that lets solvers encounter this decision problem.

In the continuous participation, the aforementioned two major incentives still act as important factors. Specifically, 15 of 17 respondents said that they would participate in CCPS in future as long as this model continuously offers their opportunities to acquire what they want. The other two respondents did not further participate because of their bad participation experience and having other better options to gain what they want.

\section{(3) Individual characteristics}

Solvers' interests, competence (including skills, expertise and experience) and employment status were identified as the most important influential individual characteristics in their initial participation decision. More specifically, a solver's interests and competence determine whether he/she is willing and able to participate in CCPS or not. The employment status would influence the necessity and likelihood of participation in CCPS. A respondent (ID 9) who was working at a state-owned company and other five freelancers said that:

I have a lot of spare time after work. I would like to take advantage of this time and my abilities to do some interesting works and earn money to subsidize daily expenses ... We are freelancers. We enjoy working at what we are good at and further earning money through crowdsourcing at our convenience. 
Table 4. The identified incentives at the decision of 'platform selection'.

\begin{tabular}{|c|c|c|c|}
\hline \multirow[b]{2}{*}{ Incentives } & \multirow{2}{*}{$\begin{array}{l}\text { Initial participation } \\
\text { In ZBJ }\end{array}$} & \multicolumn{2}{|c|}{ Continuous participation } \\
\hline & & In ZBJ & Not in ZBJ \\
\hline $\begin{array}{l}\text { Related to contest } \\
\text { characteristics }\end{array}$ & $\begin{array}{l}\text { Size of contest prize } \\
\text { Multiple winners defined in contests }\end{array}$ & $\begin{array}{l}\text { Size of contest prize } \\
\text { Multiple winners defined in contests }\end{array}$ & - \\
\hline $\begin{array}{l}\text { Related to requester } \\
\text { characteristics }\end{array}$ & - & Good reputation & $\begin{array}{l}\text { Unfair and not transparent of } \\
\text { solution evaluation } \\
\text { Lack of feedback }\end{array}$ \\
\hline $\begin{array}{l}\text { Related to platform } \\
\text { characteristics }\end{array}$ & A large number of preferred contests & $\begin{array}{l}\text { A large number of preferred contests can withdraw } \\
\text { earned prizes conveniently }\end{array}$ & $\begin{array}{l}\text { Charge deposit } \\
\text { Do not protect newcomers }\end{array}$ \\
\hline & $\begin{array}{l}\text { User-friendly interface } \\
\text { Good reputation in Chinese } \\
\text { crowdsourcing industry }\end{array}$ & $\begin{array}{l}\text { User-friendly interface } \\
\text { Good reputation } \\
\text { More opportunities to earn money than other } \\
\text { platforms }\end{array}$ & Unfair for individual solvers \\
\hline
\end{tabular}

In the continuous participation, participation experience is emerged and added as a new individual characteristic. It can be indicated by solvers' participated contests, won contests, feedback from requesters and the platform, impressive things or moments that happened during their previous participation. Particularly, unpleasant participation exerted a negative influence on solvers' continuous participation. In the interviews, when we asked the respondents whether there was an impressive thing or moment happened during their participation or not, most of them noted unpleasant participation experience, such as they did not win a contest, they did not receive any feedback from requesters, and they felt unfair and non-transparent of contests.

\subsection{Platform selection}

After a solver has decided to participate in CCPS, the next decision he/she needs to make is to select a right crowdsourcing platform that focus on problem-solving contests from a couple of alternatives. The factors that affect solvers' selection of a crowdsourcing platform are illustrated below.

\section{(1) Motives}

The motives of solvers to choose a platform are consistent with the motives presented at the first decision node. 'To earn rewards', 'to have fun', 'to develop skills' and 'to improve career prospects' were still the major motives that were mentioned by the respondents.

\section{(2) Incentives}

Table 4 lists the incentives that influence respondents' selection of ZBJ in their both initial participation and continuous participation.

In the initial participation, it can be seen that the incentives related to contest characteristics ('size of contest prize' and 'multiple winners defined in contests') and platform characteristics ('a large number of preferred contests', 'user-friendly interface' and 'good reputation in Chinese crowdsourcing industry') exerted much impact on solvers' selection of ZBJ. Whereas the incentives related to other more specific characteristics, such as contest complexity, contest autonomy, and requester's identity and fairness, were paid little attention by the respondents in this decision. One possible reason for this phenomenon is that the respondents cared much about the incentives that directly related to realisation of their expectations at first. Those incentives that are relevant with a further contribution to the specific contests are considered only when necessary. The above explanation can be indicated from the replies of the respondents who aimed to earn money and learn through engaging in $\mathrm{ZBJ}$.

Initially, I just concerned those are directly related to what I want to do. They are which contests I can participate, how to select and participate in a contest, and the likelihood of my goals (motives) can be met. As for specific details, I would check them when I encounter an issue associated with them.

On ZBJ, there are a lot of contests with large prize .... Further, most of contests defined multiple winners, such as one for 1st, two for 2nd, and three for 3rd, rather than only one person can get all money. It would increase the possibility to get some rewards, which is much better than getting nothing for my works.

My major is package design. I signed up ZBJ because it has a lot of contests related to package design, especially food packaging design. Even though I also followed another platform "huaban (https://huaban.com/)", the number of package design contests on ZBJ is larger. As well, I enjoyed some masters' ideas and proposals and they inspired me a lot.

Another important reason is the influence from the people who recommended ZBJ to the respondents. Generally, for the respondents who initially participate in CCPS, the first platform that they knew from friends, 
mentors, or advertisements always became the selected one.

I trust my friends and mentors who introduced $\mathrm{ZBJ}$ to me. They have conducted actions in this platform and get some benefits. I do not want to spend time to find and compare with other platforms. In addition, I think it is unnecessary to examine the details of the platform.

For the solvers who intended to participate in ZBJ continuously, they considered much more and specific aspects when selecting a platform. As illustrated in Table 4, the aspects including requester's reputation and fairness, payment scheme, platform's fairness, transparency of solution evaluation act as the incentives that affect solvers' decisions making. More specifically, 'good reputation of requesters' was a new incentive that played an important role in activating solvers to participate in ZBJ further.

Yes, I would like to work in ZBJ further, because it has a lot of big contests that are launched by requesters owning good reputation. These requesters include government agencies and famous companies. They make me don't worry that they do not pay. As well, participating in these big contests gives me a sense of achievement if I win.

However, 'requester's reputation' was also a complaint focus indicated by some respondents who did not engage in $\mathrm{ZBJ}$ further.

A requester selected a participant as the winner who submitted a solution was apparently not the best. A requester required me to revise my design multiple times but finally selected another participant as the winner. Some requesters indefinitely postponed annunciation of final results.

Additionally, fairness and feedback provided by requesters were concerned by respondents as well. They have influence on their perception of the reputation and trustworthiness of requesters.

In terms of platform characteristics, in the continuous participation, the respondents who wanted to participate in ZBJ thought that the platform provides them more opportunities to earn money and flexible ways to withdraw the earned money. These two added incentives appeal to the respondents with the motive of 'to earn rewards'. For the solvers who did not want to participate further, 'charge deposit', 'do not protect newcomers', and 'unfair for individual solvers' were the three most concerned aspects.

There are many veterans and solvers participated as a firm with many professional designers in ZBJ. It is unfavorable to us to compete with them. In addition, to our knowledge, ZBJ may give priority to these veterans and participatory firms in recommending some good contests. To be a member, a lot of money should be given to ZBJ ... . For a single solver, especially a student, offering membership fee or deposit before participating in a contest is difficult.

(3) Individual characteristics

Solvers' individual characteristics such as interests and competence affect solvers' selection of a platform through influencing their perception of the platform and its launched contests. Another individual characteristic that affects solvers' selection of a platform is their social network especially their friends/mentors. Participation experience especially the successful or failed one became an important characteristic that accounts for solvers' decision of continuous participation in the same platform. Good participation experience may positively affect the solvers' sustained participation in a platform while an unpleasant participation experience may have an opposite effect.

One of reasons I want to engage in $\mathrm{ZBJ}$ further is that I won several contest. I did not win any on other platforms. Further, I have been used to the ZBJ ... In contrast, I did not engage in ZBJ anymore, because I did not win a contest in $\mathrm{ZBJ}$, and there are some underlying shady deals which are not fair to us.

\subsection{Contest selection}

The detailed information about solvers' motives, incentives, and solvers' individual characteristics that affect their contest selection is demonstrated below.

\section{(1) Motives}

The motives of solvers to make the decision of contest selection are consistent with the solvers' motives to participate in CCPS and select a crowdsourcing platform.

\section{(2) Incentives}

Table 5 shows the incentives mainly concerned by the respondents in this decision.

As shown in Table 5, the incentives are mainly related to contest and requester characteristics. The direct impact of platform characteristics is weak since solvers have already considered them in the former decision, that is, platform selection. Particularly, contest characteristics, mainly including prize, complexity, the number of defined winners, instruction and autonomy, duration and in-process status, were mostly considered by the respondents when they selected a contest to participate. 
Table 5. The identified incentives in the decision of contest selection.

\begin{tabular}{|c|c|c|}
\hline Incentives & Initial participation & Continuous participation \\
\hline $\begin{array}{l}\text { Related to contest } \\
\text { characteristics }\end{array}$ & $\begin{array}{l}\text { contest prize: high vs. low and medium } \\
\text { contest complexity: high vs. low } \\
\text { No. of defined winners in a contest: multiple vs. single } \\
\text { contest instruction and autonomy: clear and specific } \\
\text { contest duration: long vs. short } \\
\text { contest in-process status: small number of } \\
\text { participants; low competition; low quality of } \\
\text { submitted solutions }\end{array}$ & $\begin{array}{l}\text { The incentives concerned by solvers did not change too much, but their } \\
\text { preferences on the values of some incentives may change with } \\
\text { development of their interests, competence, and participation } \\
\text { experience. }\end{array}$ \\
\hline Related to requester & Good reputation & Good reputation \\
\hline characteristics & Fairness and transparency & Fairness and transparency \\
\hline
\end{tabular}

Under each contest characteristic, different respondents prefer different values. For instance, three respondents (ID6, ID8 and ID14) liked to participate in the contests with high prize. While the rest did not care the size of contest prize too much, because they thought that their skills and experience may not enough to handle the complexity of a contest with high prize and further to win. With respect to the characteristic of 'the number of defined winners in a contest', 16 respondents indicated that they were apt to involve in the contests with setting multiple winners. Only one respondent (ID8) noted that he expected to engage in the contests with one winner because he is confident with his competence.

Another contest characteristic needs to be noted is 'contest in-process status'. The respondents tended to participate in the started contests with low competition, a small number of participants, and low quality of submitted solutions in order to increase the likelihood of winning. Nevertheless, a contest's in-process status may not bring too much influence on solvers' decision to participate. One of major reasons is that it is an exhausting work to assess each contest's in-process status, because there are a lot of contests were launched at a time. More importantly, problem-solving contests such as logo design and packaging design have no absolutely correct solutions. Evaluation and rank of solutions is a subject work that depends on requesters' preferences and expectations. Another reason is that ZBJ offers solvers and requesters the right of hiding their solutions in an ongoing contest in order to avoid plagiarism and protect intellectual properties.

Even though a few solvers have engaged in this contest and submitted some solutions, I would like to select it if I have an inspiration or good idea. The winning solutions are determined by requesters. No one can tell exactly what requesters like even themselves. Actually, those veterans or professional solvers who are likely to submit solutions with high quality always have high member levels. They have rights to hide their solutions to avoid to be checked by peers, leading to we don't know those solutions with high quality.
Additionally, the incentives, that is, reputation, fairness and transparency of requesters, were concerned by the respondents as well, because those incentives are helpful for alleviating their worries and hesitations when making a decision to participate in a contest. A requester's reputation can be indicated from his/her certifications and contest prize guaranteed. Further, disclosing the requester's identity and feedback and publishing specific criteria and committee for evaluating solutions can be used to demonstrate a requester's fairness and transparency in an ongoing contest. Unfortunately, the presentation of the above information is uncommon in ZBJ.

For the decision of contest selection in the continuous participation, the incentives that affect the respondents' decision making do not have much difference. But some respondents' preferences on the values of incentives may change. For example, some respondents (ID5, ID10 and ID16) preferred simple contests at the beginning but complex ones later with the accumulation of their competence and participation experience.

\section{(3) Individual characteristics}

Solvers' interests, competence and design style influence their decision of contest selection. In this study, design style, for example, cartoon style, refers to solvers' preferences and abilities in logo, package and graphic design. Influences of individual characteristics on contest selection mainly include three folds. Firstly, solvers usually select the contests that fit their interests, skills and design styles. Secondly, the individual characteristics mentioned above are important for solvers to create inspirations or ideas on design problems. Thirdly, solvers' characteristics would affect their perception of different contest characteristics such as prize and complexity. For example, the respondents with a high level of skills and rich experience tended to choose the contests with high prize and complexity. In contrast, some respondents especially rookies preferred simple contests. 


\subsection{Determination of effort level}

Solvers may make three levels of effort in their selected contests. They are looking into the contests and other submitted solutions, commenting on other submitted solutions, and developing and submitting solutions, respectively. In the initial participation, all respondents would submit a solution to the participated contests and look into other submitted solutions. Although no respondents commented on other solvers' solutions with explicit texts or other forms, three respondents (ID6, ID7 and ID13) would rank those submitted solutions in private. By contrast, in the continuous participation, two respondents (ID3 and ID11) noted that they did not check other submitted solutions because of the lack of enough time and avoiding to be influenced by them. Additionally, most of the respondents always did their best to complete their selected contests. Nevertheless, 8 of them indicated that they would not try their best in some contests, especially in the later stages of contests.

The factors influencing solvers' determination of effort level in a contest are illustrated below.

\section{(1) Motives}

Solvers' motives in this decision are consistent with the aforementioned three decisions, which mainly are 'to earn rewards', 'to have fun', 'to develop skills' and 'to improve career prospects'. Further, the former three motives played a central role. Specifically, the respondents who had the motive of 'to earn rewards' can only be satisfied through submitting solutions which are better than others. As a result, they would look into other submitted solutions and make great effort on their own solutions. For the respondents who wanted to learn and develop skills, checking other solvers' solutions and developing their own solutions are two important approaches. Further, for the phenomenon that most respondents did not comment on other solvers' solutions, one possible reason is that some of the solvers did not find the ways to give a comment or some did not have a habit of commenting on others. Another important reason is that this behaviour did not directly serve the purpose of earning money or learning.

\section{(2) Incentives}

The major incentives that were concerned by the respondents include contest prize, the number of defined winners, contest in-process status especially competition intensity, and requester feedback. The incentives and their functions mean different for different respondents with different motives and characteristics.

I wanted to earn some rewards in this contest. If I did not do my best, I cannot win because there are many veterans who were participating in this contest. If the prize of this contest is high, I would do my best to submit a solution with high quality. In contrast, I may not try my best, because this prize does not worth it.

Of these incentives, feedbacks provided by requesters, including evaluation on solvers' solutions, responses to solvers' requests in time, publishing contest progress information and supplementing some materials, were concerned and expected by some respondents. In a specific contest, requesters' feedback would deliver three kinds of information to solvers: the contest is being performed, requesters are worth to be trusted, and requesters respect them and pay attention to their solutions. Consequently, these feedbacks would have an impact on solvers' effort levels in a contest and also may affect their intention of further participation and contribution.

In the continuous participation, the influential incentives commonly are the same as the ones in the initial participation. It is noted that the incentives related to the reputation of requesters and platform characteristics were not considered in this decision, because they have been taken into account in the aforementioned decisions.

\section{(3) Individual characteristics}

Individual characteristics including employment status, interests, and personal working manner were the most important factors that influence the respondents' decision making. More specifically, employment status is directly associated with a solver's time and energy putting into a contest. The respondents having a formal work indicated that they may not exert great effort in a contest if they cannot spare enough time from their formal work. Another important characteristic mentioned by five respondents (ID1, ID2, ID7, ID9 and ID13) is personal working manner. Solvers' interests are also an important individual characteristic. Three respondents (ID10, ID14 and ID16) demonstrated that they would prefer to exert more efforts on the contests that they are interested in.

\section{Discussion and implications}

\subsection{Discussion of the results}

This study focused on investigating the decisions that solvers are likely to make in the process of participation in CCPS. It is different from prior studies that mainly concentrated on the results of those decisions, that is, 
solvers' various actions, such as participate in a crowdsourcing platform (Alam and Campbell 2017; Franke, Keinz, and Klausberger 2013; Mazzola et al. 2020; Zheng, Li, and Hou 2011), engage in a task (Pee, Koh, and Goh 2018; Schulze, Krug, and Schader 2012) and develop solutions (Acar 2019; Bockstedt, Druehl, and Mishra 2015; Garcia Martinez 2017; Liu et al. 2020; Mack and Landau 2020). The framework proposed in this study enables us to understand solvers' participation in CCPS from a decision process perspective. Furthermore, the framework emphasises and demonstrates the interactions among solvers' major decisions. They are decisions of 'participation in CCPS', 'platform selection', 'contest selection' and 'determination of effort level'. Specifically, outcomes of the former decisions to some extent influence their followed decision makings. In turn, outcomes of solvers' latter decisions would support and improve their future decision makings in the next decision loop with positive or negative feedback. This view may indicate that it is imperative to consider the relations among these decisions and link them together when we seek to impose upon solvers' a specific decision and behaviour.

Regarding any one of the decisions mentioned above, three groups of interrelated factors including solvers' motives, incentives and solvers' individual characteristics were identified to influence solvers' decision making. More specifically, motivational factors are the stable psychological driver within solvers that stimulate goaldirected actions (Ryan and Deci 2000). Incentives act as the external properties that can be perceived by solvers and are useful for activating solvers' motives (Leimeister et al. 2009; Zhang 2008). Finally, solvers' individual characteristics would determine their motives, influence their perception of various incentives, and affect their understanding of decision problems. In addition, we presented the specific motives, incentives, and individual characteristics that influence solvers' decision making. The identified factors in each of the three factor categories may be helpful for extending and improving further academic studies on factors that affect solvers' actions in crowdsourcing as a supplement and reference.

\section{(1) Motivational factors}

In this study, five motives, that is, 'to earn rewards', 'to develop skills', 'to improve career prospects', 'to have fun' and 'self-efficacy', were identified from interviews with solvers in $\mathrm{ZBJ}$. The first three motives were highlighted as most important drivers for solvers' decision makings. However, it is worthy noted that there is no a definitive set of motives that works in all crowdsourcing cases. It partly depends on the characteristics of crowdsourcing cases. For example, in Threadless and iStockphoto, participants' motives including 'to make money', 'to develop creative skills', 'to leverage freelance design work', 'the love of the community' and 'addition to online community' were found to stimulate their participation (Brabham 2010). Another example is wiki OpenStreetMap, a site for voluntary geographic information, where mappers were oriented to community, learning, local knowledge, career and free availability of mapping data motivations (Budhathoki and Haythornthwaite 2013).

Additionally, solvers' specific motivations rely on their characteristics such as skills, employment status and participation experience, which is consistent with the findings in previous studies. For example, Budhathoki and Haythornthwaite (2013) noted that serious and casual mappers have different motives to participate in OpenStreetMap. Battistella and Nonino (2013) showed that users with different roles are attracted by various motives. Wijnhoven, Ehrenhard, and Kuhn (2015) verified that participants with different citizens' characteristics have different motives to involve in open government projects.

Last but not least, as indicated in this study, a solver's motives to participate in crowdsourcing are not fixed but would evolve with the development of his/her participation experience and times. It is in line with the findings in (Alam and Campbell 2017; Tinati et al. 2017) which noted that solvers' motives would change with their accumulated times of participation.

\section{(2) Incentives}

The second factor is the incentives that can appeal to or match solvers' motives (Leimeister et al. 2009; Rosestiel Von 2007; Zhang 2008). Thus, we can infer, to a certain extent, what incentives are concerned by solvers after knowing their motives. As indicated in this study, for example, solvers with the motive of earning money paid much attention on the incentives of the contest prize, the number of defined winners in the contest, prize guaranteed and contest in-process status when selecting a contest to participate. For solvers who prioritize the motive of learning, they may give priority to the incentives of opportunities to practice skills and feedback from other solvers and requesters.

In addition, we also found that the priorities of incentives for solvers depend on decision problems they encountered. In other words, solvers care the incentives that intimately connect with their current works. For example, solvers focused on what and how they can gain when making a decision to participate in CCPS. During the selection of platform, contest characteristics 
and platform characteristics were taken into account firstly rather than requester characteristics. However, during decisions of 'contest selection' and 'determination of effort level', solvers mainly consider the incentives that are closely related to requesters' characteristics such as their fairness, transparence of operating tasks and feedback.

The last finding about incentives in this study is that multiple incentives generally combine together to respond to a motive. For instance, during selecting a contest, solvers who want to earn money would consider not only the incentives that influence how much they may gain such as contest prize, the number of defined winners and service fees, but also the ones that ensure the earned money such as prize guaranteed and requesters' reputation and fairness. Consequently, the above analysis provides a reference for crowdsourcing platforms to design a bundle of incentives in order to attract and keep solvers' participation by examining solvers' motives and individual characteristics.

\section{(3) Individual characteristics}

This study also investigated solvers' individual characteristics and their roles in influencing solvers' decision makings. Previous studies have examined a few individual characteristics that affect solvers' actions in crowdsourcing, including past participation experience (Wang and Wang 2019; Ye and Kankanhalli 2017; Zhu, Li, and Andrews 2017) especially past success experience (Wang, Khasraghi, and Schneider 2020; Zhu, $\mathrm{Li}$, and Andrews 2017), expertise ( $\mathrm{Zhu}, \mathrm{Li}$, and Andrews 2017), and cultural background (Chua, Roth, and Lemoine 2015; Bockstedt, Druehl, and Mishra 2015). This study emphasised the influence of four solvers' individual characteristics, that is, design style, social network, personal working manner and participation experience, in their decisions to participate.

The results show that the first characteristic, that is, design style, affects solvers' selection of a contest and determination of effort levels to be invested, because it is related to their preferences, skills and previous contests that solvers have performed in ZBJ. The social network of a solver, particularly in terms of his/her intimate friends or mentors, acts as a generator of peer influence (Bapna and Umyarov 2015; Duhaime et al. 2019). Peer influence mainly specialises as a conformity with behaviours, attitudes or emotions of friends or mentors (Risselada, Verhoef, and Bijmolt 2014). In this study, the related finding is that solvers' social network brings effect on their recognition of crowdsourcing models and further on their decision to select and participate in a crowdsourcing platform.
For the third individual characteristic, personal working manner of solvers refers to their attitude and responsibility to work at a contest. It is one of personality factors which have been examined to be related to individual's work performance and intention (Landers and Lounsbury 2006; Mount, Ilies, and Johnson 2006). In this study, completing a problem-solving contest, for example, graphic design, is a work that costs solvers' much time and effort. Moreover, whether winning a contest or not is full of fierce competition and uncertainty. Thus, solvers' working manner turns to be important and a solver has to make up his/her mind and persevere to develop solutions with high quality. As indicated by some respondents, they would try their best to develop solutions for a contest that they have chosen it.

The final one is participation experience that plays a very important role in stimulating solvers from initial participation to continuous participation. Totally, it can be divided into positive and negative participation experience. The positive participation experience would have a positive effect on solvers' intention to participate continuously (Wang and Wang 2019; Wang, Khasraghi, and Schneider 2020; Ye and Kankanhalli 2017; Zhu, Li, and Andrews 2017). In contrast, solvers may not participate continuously due to the negative participation experience. In CCPS, the positive participation experience can be accumulated by winning contests, receiving feedback from requesters, having a feeling of being respected, and trusting requesters and crowdsourcing platforms.

\subsection{Implications for practice}

Founded on the above results, this study provides some practical implications for crowdsourcing platforms to manage and serve solvers in problem-solving contests.

The first implication is managing solvers' participation from a decision process view. As indicated in this study, the process of solvers' participation involves several interrelated decisions. Although many management attempts have been made on solvers' single decision, knowledge and practices about how to connect their interrelated decisions and transfer one decision to another one are limited. It would result in difficulty for fully making use of the wisdom of solvers. For example, one of the practical facts is that a large proportion of solvers did not participate in a contest after signing up let alone make a contribution. Therefore, for a crowdsourcing platform, it is an imperative work to focus on solvers' initial participation and adopt effective incentives to promote them to participate deeply. In a word, if a crowdsourcing platform expects solvers to 
participate continuously, a lot of efforts should be made to ensure that solvers have a good participation experience in their initial participation. Moreover, according to the findings of this study, solvers' motives and characteristics need to be considered when crowdsourcing platforms make those efforts.

Secondly, we found that solvers with different participation levels, such as newcomers and veterans, have different motives, skills, expertise, and participation experience. This finding is consistent with the results presented by Budhathoki and Haythornthwaite (2013) and Battistella and Nonino (2013). In practical, most of the crowdsourcing platforms grade solvers into various levels based on their past performance or membership levels. For example, 99designs, Guerra creative, Crowdspring and Designhill adopt a performance-based principle to grade solvers, while Freelancer, Zooppa, and GoPillar grade solvers based on their membership levels. The solvers with high levels would enjoy more privileges than those with low levels. It is unfair for newcomers to compete with veterans at the beginning and thus may discourage them. Therefore, one thing that needs to be highlighted for a crowdsourcing platform is to balance the services for solvers with different levels. For example, for newcomers, crowdsourcing platforms could design some specific measures to facilitate them to conduct actions and learn, such as recommending contests to solvers according to their levels, building a newcomer centre with some tips and tricks for developing creative solutions, and developing a community for different solvers to share and exchange ideas and expertise.

Another implication is that being transparent is very important. The transparency of contest operation is concerned by solvers when they make a decision to participate in a crowdsourcing platform or a contest. As indicated in this study, we present some suggestions for crowdsourcing platforms to increase solvers' perception of a contest's transparence. They mainly include requiring prize guaranteed, disclosing requesters' identity, publishing criteria and jury for selecting winners, giving feedback and publishing code of conduct for regulating solvers' and requesters' behaviours and avoiding cheat and plagiarism.

Last but not least, a combination of incentives should be presented for solvers with a specific motive. For example, regarding solvers who aim to earn money by participating in a contest, they not only concern contest prize, but also the possibility of getting the prize. So the incentives including ensuring prize guaranteed, charging appropriate service fees, setting multiple winners, and withdrawing the won prize conveniently are suggested to be considered comprehensively with the size of prize. Furthermore, it is necessary to pay attention on the relations among these incentives. For instance, in a contest, the charged service fees should not be linear but should adjust with the size of prizes. That is better off lowering the fee rate for contests with high prizes (Wen and Lin 2016).

\subsection{Limitations and future research}

This study suffers from a couple of limitations. First, the study was conducted on a specific Chinese crowdsourcing platform. It may differ from some international crowdsourcing platforms in other countries in terms of task types, prize and fee structures, requester management policies and especially engaged solvers. Furthermore, solvers with different cultural background and wealth would have different motives and behaviours in a problem-solving contest (Chua, Roth, and Lemoine 2015; Bockstedt, Druehl, and Mishra 2015). The above situations are likely to limit the generalizability of our findings to other international crowdsourcing platforms concentrating on problemsolving contests. Another limitation is that this study just interviewed only a small sampling of solvers in ZBJ. In addition, the engaged solvers were active and participated in at least one contest. It may result in ignoring the views of solvers who are less active especially those who did not participate in a contest after registering. Third, the research context is limited to problem-solving tasks which particularly are logo design, packaging design, graphic design, flash production and name finding. Caution should be exercised in generalising the findings based on this context to other specific problem-solving tasks such as scientific and technology innovation problems.

The research findings and limitations invite ideas for future research on solvers' participation in CCPS. One of future studies would focus on expanding the sample of interviews and incorporating replies from solvers who have participation experience in other international crowdsourcing platforms in order to further improve the developed decision process framework. Another future study is to investigate components that are designed and presented by crowdsourcing platforms for solvers. These components are responsive to the incentives that appeal to or match solvers' motives. As a result, we expect to construct a chain of solvers' behaviours-motivations-incentives-and activation-supporting components which is useful for better understanding and managing solvers' behaviours.

\section{Conclusion}

In this study, through conducting interviews with solvers in ZBJ, we developed a framework for 
demonstrating the decision process of their participation in CCPS. It connects four major interrelated decisions, that is, 'participation in CCPS', 'platform selection', 'contest selection' and 'determination of effort level', that solvers are likely to make during their initial and continuous participation. Meanwhile, we identified three categories of factors, that is, solvers' motives, incentives and solvers' individual characteristics, which affect solvers' each decision making. Specifically, the motives that drive solvers' participation mainly include 'to earn rewards', 'to develop skills', 'to have fun', 'to improve career prospects' and 'selfefficacy'. The specific incentives that appeal to the solvers' motives vary from decision to decision and depend on solvers' motives and individual characteristics. It is worthy noted that the incentives always work together to influence solvers' decision makings and this influence may change with the development of solvers' individual characteristics. In addition, individual characteristics influence solvers' decision makings through determining solvers' motives and affecting solvers' perception of various incentives and decision problems. The major influential individual characteristics include interests, competence, employment status, social network, design style, personal working manner, and participation experience. We may believe that our analysis and findings could contribute to the crowdsourcing filed by proposing a framework for illustrating the decision process of solvers' participation in CCPS. Meanwhile, this study contributes to the practice by offering suggestions for the crowdsourcing platforms focusing on problem-solving contests to serve and manage their solvers effectively.

\section{Disclosure statement}

No potential conflict of interest was reported by the author(s).

\section{Funding}

This work was supported by Anhui Department of Education [grant number KJ2019A0137] and National Natural Science Foundation of China [grant number 71802002].

\section{Reference}

Acar, O. A. 2019. "Motivations and Solution Appropriateness in Crowdsourcing Challenges for Innovation." Research Policy 48: 103716.

Alam, S. L., and J. Campbell. 2017. "Temporal Motivations of Volunteers to Participate in Cultural Crowdsourcing Work." Information Systems Research 28: 744-759.

Bagheri, S. K., P. Raoufi, M. Samandar Ali Eshtehardi, S. Shaverdy, B. Ramezani Akbarabad, B. Moghaddam, and A. Mardani. 2020. "Using the Crowd for Business Model
Innovation: The Case of Digikala.” R\&D Management 50: 3-17.

Bapna, R., and A. Umyarov. 2015. "Do Your Online Friends Make You Pay? A Randomized Field Experiment on Peer Influence in Online Social Networks." Management Science 61: 1902-1920.

Bassi, H., C. J. Lee, L. Misener, and A. M. Johnson. 2020. "Exploring the Characteristics of Crowdsourcing: An Online Observational Study." Journal of Information Science 46: 291-312.

Battistella, C., and F. Nonino. 2012. “Open Innovation Webbased Platforms: The Impact of Different Forms of Motivation on Collaboration." Innovation 14: 557-575.

Battistella, C., and F. Nonino. 2013. "Exploring the Impact of Motivations on the Attraction of Innovation Roles in Open Innovation web-Based Platforms." Production Planning \& Control 24: 226-245.

Bayus, B. L. 2013. "Crowdsourcing New Product Ideas Over Time: An Analysis of the Dell IdeaStorm Community." Management Science 59: 226-244.

Bockstedt, J., C. Druehl, and A. Mishra. 2015. "Problem-solving Effort and Success in Innovation Contests: The Role of National Wealth and National Culture." Journal of Operations Management 36: 187-200.

Boons, M., D. Stam, and H. G. Barkema. 2015. "Feelings of Pride and Respect as Drivers of Ongoing Member Activity on Crowdsourcing Platforms." Journal of Management Studies 52: 717-741.

Brabham, D. C. 2008. "Crowdsourcing as a Model for Problem Solving: An Introduction and Cases." Convergence: The International Journal of Research Into New Media Technologies 14: 75-90.

Brabham, D. C. 2010. "Moving the Crowd at Threadless." Information, Communication \& Society 13: 1122-1145.

Budhathoki, N. R., and C. Haythornthwaite. 2013. "Motivation for Open Collaboration: Crowd and Community Models and the Case of OpenStreetMap." American Behavioral Scientist 57: 548-575.

Camacho, N., H. Nam, P. K. Kannan, and S. Stremersch. 2019. "Tournaments to Crowdsource Innovation: The Role of Moderator Feedback and Participation Intensity." Journal of Marketing 83: 138-157.

Chan, K. W., S. Y. Li, and J. J. Zhu. 2015. “Fostering Customer Ideation in Crowdsourcing Community: The Role of Peerto-Peer and Peer-to-Firm Interactions." Journal of Interactive Marketing 31: 42-62.

Chris Zhao, Y., and Q. Zhu. 2014. "Effects of Extrinsic and Intrinsic Motivation on Participation in Crowdsourcing Contest: A Perspective of Self-determination Theory." Online Information Review 38: 896-917.

Chua, R. Y. J., Y. Roth, and J.-F. Lemoine. 2015. “The Impact of Culture on Creativity: How Cultural Tightness and Cultural Distance Affect Global Innovation Crowdsourcing Work." Administrative Science Quarterly 60: 189-227.

Deodhar, S. 2020. "Different Eyes on the Same Prize: Implications of Entry Timing Heterogeneity and Incentives for Contestant Effort in Innovation Tournament." Information Technology \& People 34: 526556.

Duhaime, E., B. Bond, Q. Yang, P. de Boer, and T. W. Malone. 2019. Recruiting Hay to Find Needles: Recursive Incentives 
and Innovation in Social Networks. Available at SSRN 3545311.

Durward, D., I. Blohm, and J. M. Leimeister. 2020. "The Nature of Crowd Work and its Effects on Individuals' Work Perception." Journal of Management Information Systems 37: 66-95.

Estellés-Arolas, Enrique, and Fernando González-Ladrón-deGuevara. 2012. "Towards an Integrated Crowdsourcing Definition." Journal of Information Science 38: 189-200.

Franke, N., P. Keinz, and K. Klausberger. 2013. “"Does This Sound Like a Fair Deal?": Antecedents and Consequences of Fairness Expectations in the Individual's Decision to Participate in Firm Innovation." Organization Science 24: $1495-1516$.

Frey, Karsten, Christian Lüthje, and Simon Haag. 2011. "Whom Should Firms Attract to Open Innovation Platforms? The Role of Knowledge Diversity and Motivation.” Long Range Planning 44: 397-420.

Garcia Martinez, M. 2015. "Solver Engagement in Knowledge Sharing in Crowdsourcing Communities: Exploring the Link to Creativity." Research Policy 44: 1419-1430.

Garcia Martinez, M. 2017. "Inspiring Crowdsourcing Communities to Create Novel Solutions: Competition Design and the Mediating Role of Trust." Technological Forecasting and Social Change 117: 296-304.

Heo, M., and N. Toomey. 2015. "Motivating Continued Knowledge Sharing in Crowdsourcing: The Impact of Different Types of Visual Feedback." Online Information Review 39: 795-811.

Huang, N., G. Burtch, B. Gu, Y. Hong, C. Liang, K. Wang, D. Fu, and B. Yang. 2019. "Motivating User-generated Content with Performance Feedback: Evidence from Randomized Field Experiments." Management Science 65: 327-345.

Jian, L., S. Yang, S. L. Ba, L. Lu, and L. C. Jiang. 2019. "Managing the Crowds: The Effect of Prize Guarantees and In-Process Feedback on Participation in Crowdsourcing Contests.” MIS Quarterly 43: 97-112.

Johnson, E., and L. Liew Chern. 2020. "Engagement-oriented Design: a Study of New Zealand Public Cultural Heritage Institutions Crowdsourcing Platforms." Online Information Review 44: 887-912.

Khasraghi, H. Javadi, and A. Aghaie. 2014. "Crowdsourcing Contests: Understanding the Effect of Competitors' Participation History on Their Performance." Behaviour \& Information Technology 33: 1383-1395.

Kohler, T. 2018. "How to Scale Crowdsourcing Platforms." California Management Review 60: 98-121.

Landers, R. N., and J. W. Lounsbury. 2006. “An Investigation of Big Five and Narrow Personality Traits in Relation to Internet Usage." Computers in Human Behavior 22: 283-293.

Leimeister, J. M., M. Huber, U. Bretschneider, and H. Krcmar. 2009. "Leveraging Crowdsourcing: Activation-supporting Components for IT-Based Ideas Competition." Journal of Management Information Systems 26: 197-224.

Li, D., and L. Hu. 2017. "Exploring the Effects of Reward and Competition Intensity on Participation in Crowdsourcing Contests." Electronic Markets 27: 199-210.

Liang, H., M.-M. Wang, J.-J. Wang, and Y. Xue. 2018. "How Intrinsic Motivation and Extrinsic Incentives Affect Task Effort in Crowdsourcing Contests: A Mediated Moderation Model." Computers in Human Behavior 81: 168-176.
Liu, Q., Q. Du, Y. Hong, W. Fan, and S. Wu. 2020. “User Idea Implementation in Open Innovation Communities: Evidence from a new Product Development Crowdsourcing Community." Information Systems Journal 30: 899-927.

Liu, Y., and Y. M. Liu. 2019. “The Effect of Workers' Justice Perception on Continuance Participation Intention in the Crowdsourcing Market.” Internet Research 29: 1485-1508.

Mack, T., and C. Landau. 2020. "Submission Quality in Open Innovation Contests - an Analysis of Individual-Level Determinants of Idea Innovativeness." RÆD Management 50: $47-62$.

Malhotra, A., and A. Majchrzak. 2014. "Managing Crowds in Innovation Challenges." California Management Review 56: 103-123.

Malone, T. W., R. Laubacher, and C. Dellarocas. 2010. “The Collective Intelligence Genome." IEEE Engineering Management Review 38: 38-52.

Malone, T. W., J. V. Nickerson, R. J. Laubacher, L. H. Fisher, P. D. Boer, Y. Han, and W. B. Towne. 2017. Putting the Pieces Back Together Again: Contest Webs for LargeScale Problem Solving. Proceedings of the 2017 ACM Conference on Computer Supported Cooperative Work and Social Computing. Portland, Oregon, USA: Association for Computing Machinery.

Mazzola, E., N. Acur, M. Piazza, and G. Perrone. 2018. ““To Own or Not to Own?" A Study on the Determinants and Consequences of Alternative Intellectual Property Rights Arrangements in Crowdsourcing for Innovation Contests." Journal of Product Innovation Management 35: 908-929.

Mazzola, E., M. Piazza, N. Acur, and G. Perrone. 2020. "Treating the Crowd Fairly: Increasing the Solvers' Selfselection in Idea Innovation Contests." Industrial Marketing Management 91: 16-29.

Mount, M., R. Ilies, and E. Johnson. 2006. "Relationship of Personality Traits and Counterproductive Work Behaviors: the Mediating Effects of job Satisfaction." Personnel Psychology 59: 591-622.

Mount, M., H. Round, and T. S. Pitsis. 2020. "Design Thinking Inspired Crowdsourcing: Toward a Generative Model of Complex Problem Solving." California Management Review 62: 103-120.

Pee, L. G., E. Koh, and M. Goh. 2018. "Trait Motivations of Crowdsourcing and Task Choice: A Distal-proximal Perspective." International Journal of Information Management 40: 28-41.

Piezunka, H., and L. Dahlander. 2019. "Idea Rejected, Tie Formed: Organizations' Feedback on Crowdsourced Ideas." Academy of Management Journal 62: 503-530.

Pollok, P., D. Lüttgens, and F. T. Piller. 2019. "Attracting Solutions in Crowdsourcing Contests: The Role of Knowledge Distance, Identity Disclosure, and Seeker Status." Research Policy 48: 98-114.

Risselada, H., P. C. Verhoef, and T. H. A. Bijmolt. 2014. "Dynamic Effects of Social Influence and Direct Marketing on the Adoption of High-Technology Products." Journal of Marketing 78: 52-68.

Rosestiel Von, L. 2007. Grundlagen der Organisationspsychologie: Basiswissen und Anwendungshinweise [Basics of Organizational Psychology]. Stuttgart: Schäffer-Poeschel. 
Ryan, R. M., and E. L. Deci. 2000. "Intrinsic and Extrinsic Motivations: Classic Definitions and New Directions." Contemporary Educational Psychology 25: 54-67.

Schenk, E., and C. Guittard. 2011. "Towards a Characterization of Crowdsourcing Practices." Journal of Innovation Economics 7: 93-107.

Schörpf, P., J. Flecker, A. Schönauer, and H. Eichmann. 2017. "Triangular Love-Hate: Management and Control in Creative Crowdworking." New Technology, Work and Employment 32: 43-58.

Schulze, T., S. Krug, and M. Schader. 2012. “Workers' Task Choice in Crowdsourcing and Human Computation Markets." Presented at the 33rd International Conference on Information Systems (ICIS 2012), Orlando.

Segev, E. 2020. "Crowdsourcing Contests.” European Journal of Operational Research 281: 241-255.

Steils, N., and S. Hanine. 2019. "Recruiting Valuable Participants in Online IDEA Generation: The Role of Brief Instructions." Journal of Business Research 96: 14-25.

Sun, Y., Y. Fang, and K. H. Lim. 2012. "Understanding Sustained Participation in Transactional Virtual Communities.” Decision Support Systems 53: 12-22.

Täuscher, K. 2017. "Leveraging Collective Intelligence: How to Design and Manage Crowd-Based Business Models." Business Horizons 60: 237-245.

Terwiesch, C., and Y. Xu. 2008. "Innovation Contests, Open Innovation, and Multiagent Problem Solving." Management Science 54: 1529-1543.

Tinati, R., M. Luczak-Roesch, E. Simperl, and W. Hall. 2017. "An Investigation of Player Motivations in Eyewire, a Gamified Citizen Science Project." Computers in Human Behavior 73: 527-540.

Vrgović, P., and I. Jošanov-Vrgović. 2017. "Crowdsourcing User Solutions: Which Questions Should Companies Ask to Elicit the Most Ideas from its Users?" Innovation 19: 452-462.

Wang, X., H. J. Khasraghi, and H. Schneider. 2020. “Towards an Understanding of Participants' Sustained Participation in Crowdsourcing Contests." Information Systems Management 37: 213-226.
Wang, M.-M., and J.-J. Wang. 2019. “Understanding Solvers' Continuance Intention in Crowdsourcing Contest Platform: An Extension of Expectation-Confirmation Model." Journal of Theoretical and Applied Electronic Commerce Research 14: 17-33.

Wen, Z., and L. Lin. 2016. "Optimal Fee Structures of Crowdsourcing Platforms.” Decision Sciences 47: 820-850.

Wijnhoven, F., M. Ehrenhard, and J. Kuhn. 2015. "Open Government Objectives and Participation Motivations." Government Information Quarterly 32: 30-42.

Wooten, J. O., and K. T. Ulrich. 2017. "Idea Generation and the Role of Feedback: Evidence from Field Experiments with Innovation Tournaments." Production and Operations Management 26: 80-99.

Wu, W., and X. Gong. 2020. "Motivation and Sustained Participation in the Online Crowdsourcing Community: The Moderating Role of Community Commitment." Internet Research 31: 287-314.

Ye, H., and A. Kankanhalli. 2017. "Solvers' Participation in Crowdsourcing Platforms: Examining the Impacts of Trust, and Benefit and Cost Factors." The Journal of Strategic Information Systems 26: 101-117.

Zhang, P. 2008. "Technical Opinion Motivational Affordances: Reasons for ICT Design and Use." Communications of the ACM 51: 145-147.

Zheng, H., D. Li, and W. Hou. 2011. "Task Design, Motivation, and Participation in Crowdsourcing Contests." International Journal of Electronic Commerce 15: 57-88.

Zhu, H., A. Kock, M. Wentker, and J. Leker. 2019. "How Does Online Interaction Affect Idea Quality? The Effect of Feedback in Firm-Internal Idea Competitions." Journal of Product Innovation Management 36: 24-40.

Zhu, J. J., S. Y. Li, and M. Andrews. 2017. "Ideator Expertise and Cocreator Inputs in Crowdsourcing-Based New Product Development." Journal of Product Innovation Management 34: 598-616.

Zou, L., J. Zhang, and W. Liu. 2015. "Perceived Justice and Creativity in Crowdsourcing Communities: Empirical Evidence from China." Social Science Information 54: 253-279. 